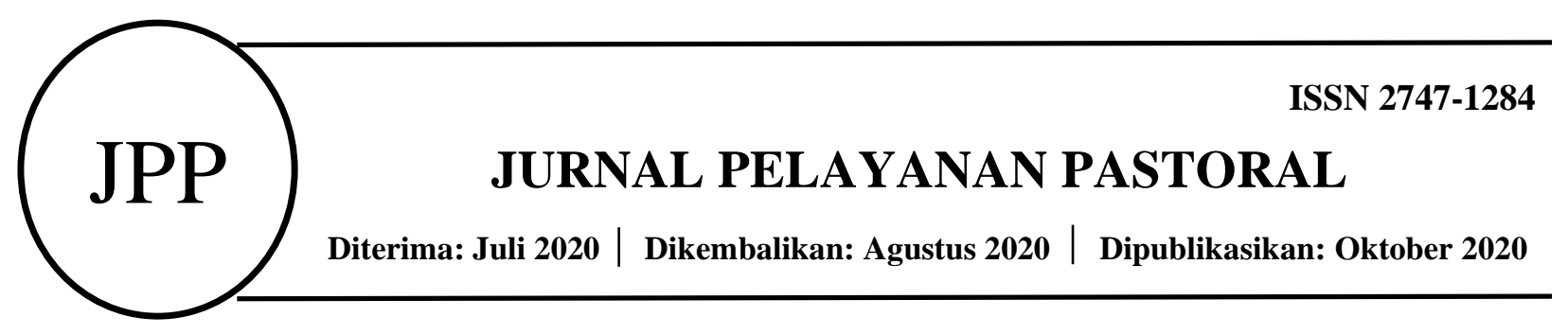

\title{
PARENTING TRAINING: MELIHAT PENGARUHNYA TERHADAP GERAK MOBILISASI SENDI BAGI PENYADANG CEREBRAL PALSY DI KABUPATEN MALANG
}

\author{
Sri Wahyuni*1, Klemensia Nini*2 \\ ${ }^{*} 12$ Sekolah Tinggi Pastoral -IPI Malang \\ Jurusan Pastoral Sosial, Prodi Pelayanan Pastoral \\ e-mail: ${ }^{1}$ sriwahyuni19370@gmail.com, ${ }^{2}$ haremensi@gmail.com
}

\begin{abstract}
Abstrak
Tujuan penelitian ini ialah untuk memperoleh data mengenai pengaruh parenting training terhadap mobilisasi sendi anak Cerebral Palsy. Subjek penelitiannya ialah orangtua dari anak Cerebral Palsy. Teknik pengambilan data dengan observasi dan kuesioner. Instrumen yang dipakai terkait metode kuesioner ini ialah angket dengan skala bertingkat. Sedangkan instrumen untuk observasi dalam bentuk chek list. Variable bebasnya parenting training (X) sedangkan variable terikatnya ialah peningkatan luas gerak sendi (Y) Sample yang dipakai ialah sample random sampling. Jenis penelitiannya ialah penelitian kuantitatif. Desain penelitiannya ialah studi korelasional. Jenis hubungan yang dipakai dalam penelitian ini adalah hubungan simetris. Jumlah populasinya 25 orang, sedangkan samplenya berjumlah 23 orang. Dalam hal analisa data, peneliti mencari dan menghitung koefisien korelasi antar variable. Hasil yang diperoleh dari penelitian ini adalah Besarnya hubungan atau pengaruh parenting training terhadap mobilisasi sendi anak Cerebral Palsy sebesar .Jadi, pengaruhnya ada pada level "cukup". Persentase hasil dari Keamatan. Singosari 73,4\%, dan Kecamatan. Lawang sebesar $67 \%$.
\end{abstract}

Kata kunci: Parenting Training, Mobilisasi Sendi, Orangtua, Cerebral Palsy.

\begin{abstract}
The purpose of this study was to obtain data on the effect of parenting training on the joint mobilization of Cerebral Palsy children. The subject of his research was the parents of Cerebral Palsy children. Data collection techniques by observation and questionnaire. The instrument used in connection with this questionnaire method is a multilevel scale questionnaire. While the instrument for observation is in the form of a check list. The independent variable is parenting training $(\mathrm{X})$ while the dependent variable is the increase in joint area (Y). The sample used is random sampling. This type of research is quantitative research. The research design is a correlational study. The type of relationship used in this study is a symmetrical relationship. The population is 25 people, while the sample is 23 people. In terms of data analysis, researchers look for and calculate the correlation coefficient between variables. The results obtained from this study are the magnitude of the relationship or effect of parenting training on the joint mobilization of Cerebral Palsy children by 25. So, the effect is at the level of "sufficient" 23 Percentage of results from sub-district. Singosari 73.4\%, and sub-district Lawang at 67\%.
\end{abstract}

Keywords: Parenting Training, Joint Mobilization, Parents, Cerebral Palsy 


\section{PENDAHULUAN}

Keluarga merupakan lingkungan yang paling dekat dengan anak, Keluarga terutama orangtua bertugas untuk memberikan perlindungan serta kasih sayang kepada anak. Keluarga mempunyai pengaruh yang besar dalam pengasuhan kepada terutama anak dengan disabilitas. Untuk memenuhi kebutuhan mereka secara mandiri. orangtua wajib mendampingi anak, mengasuh anak, dan memberikan hak-hak yang seharusnya mereka miliki. Banyak keluarga khususnya para orangtua yang memandang "rendah" dan hanya bisa bergantung pada orang lain. ABK juga sama seperti kita mempunyai hak untuk mendapatkan pengahargaan. Menurut Heward (2003) menyatakan bahwa efektivitas berbagai program penanganan dan peningkatan kemampuan hidup anak berkebutuhan khusus akan sangat ditentukan oleh peran serta dan dukungan penuh dari keluarga, sebab keluarga adalah pihak yang mengenal dan memahami berbagai aspek dalam diri seseorang dengan jauh lebih baik daripada orang-orang yang lain. Pengasuhan anak disabilitas khususnya anak Cerebral Palsy oleh orangtuanya mestinya didukung oleh pengetahuan tentang disabilitas yang memadai dan sarana pendukung yang memadai pula. Idealnya seperti itu. Akan tetapi, realitas di lapangan berbeda dari yang diharapkan. Inilah salah satu persoalan yang kami terima dari hasil sharing dosen-dosen Program Studi Pelayanan Pastoral yang selama ini menangani proyek penangan anak disabilitas di tingkat kota, kecamatan dan kabupaten di Malang. Banyak orangtua dari anak Cerebral Palsy yang belum paham mengenai anak disabilitas. Pengetahuan orangtua anak Cerebral Palsy masih minim karena orangtua belum pernah menerima kegiatan pelatihan dalam menangani anak Cerebral Palsy.

Persoalan yang diangkat dalam penelitian ini ialah seberapa besar pengaruh parenting training terhadap perkembangan mobilisasi sendi anak Cerebral Palsy? Apakah ada atau tidak pengaruh yang signifikan dari kegiatan parenting training terhadap perkembangan mobilisasi sendi anak Cerebral Palsy?

Setelah merumuskan latar belakang dan rumusan masalah, maka peneliti memaparkan tujuan dari penelitian ini. Di bawah ini kami beberkan beberapa tujuan dari penelitian ini. pertama, penelitian ini bertujuan untuk mendeskripsikan dan memaparkan data pengaruh parenting training terhadap perkembangan mobilisasi sendi dan motorik kasar anak Cerebral Palsy. Kedua, penelitian ini juga bertujuan untuk menejelaskan tingkat korelasi antara pemahaman orangtua dari anak Cerebral Palsy terhadap perkembangan pola asuh anak Cerebral Palsy dalam keluarga. Ketiga, penelitian ini bertujuan untuk menjelaskan tingkat signifikansi kegiatan parenting training dengan perkembangan mobilisasi sendi dan motorik kasar anak Cerebral Palsy.

\section{METODE PENELITIAN}

Dalam penelitian ini peneliti menggunakan pendekatan dan jenis penelitian kuantitatif. Penelitian kuantitatif adalah suatu proses menemukan pengetahuan yang menggunakan data berupa angka sebagai alat menganalisis keterangan mengenai apa yang ingin diketahui (Kasiram, 2008, 149) dalam bukunya Metodologi Penelitian Kualitatif dan Kuantitatif. Adapun lokasi penelitian ini adalah di dua kecamatan di Kabupaten Malang yaitu di kecamatan Lawang dan kecamatan Singosari.

Sumber data dalam penelitian ini ada dua yakni sumber data primer dan skunder. Data primer diperoleh dari orangtua yang memilki anak Cerebral Palsy. Instrumen yang dipakai oleh peneliti untuk memperoleh data ini dalam bentuk kuisioner. Kuisioner disebarkan kepada responden berdasarkan data responden dari empat kecamatan di Kabupaten Malang. Sedangkan, data skunder dipakai sebagai data pendukung data primer yang diperoleh melalui dokumentasi 
seperti daftar hadir orang yang anaknya Cerebral Palsy dalam kegiatan parenting training dan juga foto- foto pada saat fasilitator memberikan pembekalan atau materi parenting training.

Jumlah responden dalam penelitian ini yakni 22 orang. Keduapuluh dua responden ini diambil atau dipilih secara proposional dari dua kecamatan yaitu kecamatan Lawang dan kecamatan Singosari. Responden yang mengisi kuisioner ini adalah orang tua yang memiliki anak Cerebral Palsy. Kuisioner yang dibagikan kepada responden berjumlah 25 kuisioner. Jumlah kuisioner yang dikembalikan sebanyak 22 kuisioner. Peneliti mengambil semua responden. Tabel. Pemetaan Kuesioner

\begin{tabular}{|c|c|c|c|c|c|}
\hline No & Kec. & $\begin{array}{c}\text { Jumlah } \\
\text { Responden }\end{array}$ & $\begin{array}{c}\text { Yang } \\
\text { dibagikan }\end{array}$ & $\begin{array}{c}\text { Yang } \\
\text { dikembalikan }\end{array}$ & Persentasi \\
\hline 1 & Lawang & 12 orang & 12 orang & 12 orang & $100 \%$ \\
\hline 2 & Singosari & 11 orang & 11 orang & 11 orang & $100 \%$ \\
\hline \multicolumn{3}{|c|}{ Total } & 23 orang & 23 orang & $100 \%$ \\
\hline
\end{tabular}

Untuk metode yang dipakai dalam pengumpulan data adalah metode kuisioner, sedangkan isntrumennya ialah angket dan skala bertingkat. Jenis kuisionernya tertutup dimana peneliti sudah menyediakan jawaban sehingga responden tinggal memilih. Jika dipandang dari segi jawaban, maka kuisioner ini tergolong kuisioner langsung dimana responden menjawab tentang dirinya sendiri. Jika dipandang dari bentuknya, maka peneliti memakai bentuk rating-scale yaitu sebuah pernyataan diikuti oleh kolom-kolom yang menunjukan tingkatan-tingkatan dari sangat setuju sampai ke sangat tidak setuju.

Adapun hipotesa yang penulis ajukan ada 2 yaitu $\mathrm{Ha}$ : Kegiatan parenting training berpengaruh secara signifikan terhadap perkembangan mobilisasi sendi Cerebral Palsy. Ho : Kegiatan parenting training tidak berpengaruh secara signifikan terhadap perkembangan mobilisasi sendi anak Cerebral Palsy.

\section{HASIL DAN PEMBAHASAN}

\section{Parenting Training}

Wiliam Lopez, 2004 dalam jurnalnya Successful Parenting Skills that Shape Children's Behaviors, menyebutkan bahwa pengasuhan yang efektif sangat penting untuk kesuksesan dalam sebuah keluarga. Pengasuhan yang tepat dapat membentuk generasi yang akan datang, dan cara generasi berikutnya akan berperilaku, dan mempengaruhi dunia di sekitar mereka. Sejarah telah mengajarkan kita pengasuhan yang tanpa dasar yang tepat selalu dan selamanya menimbulkan kebingungan untuk setiap perkembangan anak. Itulah sebabnya upaya mencoba untuk menjadi orangtua yang sukses adalah sangat penting dan akan menjadi pekerjaan yang paling penting dari kehidupan seseorang. Dalam pengasuhan orangtua terhadap anak, tentunya tidak terbatas pada anak-anak normal saja tetapi juga pada anak-anak yang memiliki kebutuhan khusus misalnya penyandang disabilitas Besarnya pengaruh pengasuhan pada kehidupan anak, menuntut adanya sebuah pembelajaran tambahan bagi orangtua untuk lebih mengerti dan memahami "parenting" dengan lebih mendalam, sehingga dapat merubah pola pengasuhan ke arah yang lebih baik, efektif dan benar yang penuh kasih serta membahagiakan anak. Menurut Elly Risman (dalam Munif Chotib, 2012) kita semua, ternyata tidak siap menjadi orangtua, kita bersekolah untuk menjadi ahli di bidang masing-masing, tetapi tidak untuk menjadi ayah-ibu. Ilmu dan teknologi berkembang, 
kita tetap menggunakan "cara lama" dalam mengasuh anak kita yang kini disebut Gen-Z (generasi yang dilahirkan setelah tahun 1998 sampai sekarang). Karenanya, kita hanyut dalam "tren".

\section{Mobilisasi sendi}

Pertama, Definisi Mobilisasi sendi

Mobilisasi sendi adalah gerakan dalam keadaan normal dapat dilakukan oleh sendi yang bersangkutan (Suratun, dkk, 2008). Latihan mobilisasi sendi atau range of motion (MOBILISASI SENDI) adalah latihan yang dilakukan untuk mempertahankan atau memperbaiki tingkat kesempurnaan kemampuan menggerakan persendian secara normal dan lengkap untuk meningkatkan massa otot dan tonus otot (Potter \& Perry, 2005).

Latihan Mobilisasi sendi biasanya diberikan pada anak/orang dengan keterbatasan mobilisasi tidak mampu melakukan beberapa atau semua latihan rentang gerak dengan mandiri, pasien tirah baring total atau pasien dengan paralisis ekstermitas total. Selain berfungsi sebagai pertahanan atau dapat memperbaiki tingkat kesempurnaan kemampuan menggerakan persendian secara normal, lengkap, dan untuk meningkatkan massa otot serta tonus otot,

Kedua, Tujuan Latihan Mobilisasi sendi. Adapun tujuan dari Latihan Mobilisasi sendi yaitu:

a. Meningkatkan atau mempertahankan fleksibiltas dan kekuatan otot

b. Mempertahankan fungsi jantung dan pernapasan

c. Mencegah kekakuan pada sendi

d. Merangsang sirkulasi darah

e. Mencegah kelainan bentuk, kekakuan dan kontraktur

Ketiga, Prinsip Latihan Mobilisasi sendi. Adapun prinsip latihan, Mobilisasi sendi di antarannya:

a. Mobilisasi sendi harus diulang sekitar 8 kali dan dikerjakan minimal 2 kali sehari

b. Mobilisasi sendi di lakukan berlahan dan hati-hati sehingga tidak melelahkan pasien.

c. Dalam merencanakan program latihan mobilisasi sendi perhatikan umur pasien, diagnosa, tanda-tanda vital dan lamanya tirah baring.

d. Bagian-bagian tubuh yang dapat di lakukan latihan mobilisasi sendi adalah leher, jari, lengan, siku, bahu, tumit, kaki, dan pergelangan kaki.

e. Mobilisasi sendi dapat di lakukan pada semua persendian atau hanya pada bagian-bagian yang di curigai mengalami proses penyakit.

f. Melakukan mobilisasi sendi harus sesuai waktunya. Misalnya setelah mandi atau perawatan rutin telah di lakukan.

Empat, Macam-macam Gerakan mobilisasi sendi. Ada berbagai macam gerakan mobilisasi sendi, yaitu :

a. Fleksi, yaitu berkurangnya sudut persendian.

b. Ekstensi, yaitu bertambahnya sudut persendian.

c. Hiperekstensi, yaitu ekstensi lebih lanjut.

d. Abduksi, yaitu gerakan menjauhi dari garis tengah tubuh.

e. Adduksi, yaitu gerakan mendekati garis tengah tubuh.

f. Rotasi, yaitu gerakan memutari pusat dari tulang.

g. Eversi, yaitu perputaran bagian telapak kaki ke bagian luar, bergerak membentuk sudut persendian.

h. Inversi, yaitu putaran bagian telapak kaki ke bagian dalam bergerak membentuk sudut persendian.

i. Pronasi, yaitu pergerakan telapak tangan dimana permukaan tangan bergerak ke bawah.

j. Supinasi, yaitu pergerakan telapak tangan dimana permukaan tangan bergerak ke atas. 
k. Oposisi, yaitu gerakan menyentuhkan ibu jari ke setiap jari-jari tangan pada tangan yang sama.

\section{Cerebral Palsy}

Pertama, Definisi Cerebral Palsy

Cerebral Palsy (CP) adalah suatu kelainan gerak dan postur tubuh yang tidak progresif, dan disebabkan oleh karena kerusakan atau gangguan disel-sel motorik pada susunan saraf pusat yang sedang dalam proses pertumbuhan (Departemen Kesehatan Republik Indonesia, 2005). CP adalah kelompok gangguan motorik yang menetap, tidak progresif, yang terjadi karena kerusakan otak akibat trauma lahir. Gangguan ditandai dengan perkembangan motorik yang abnormal atau terlambat, seperti athetoid paraplegic, spastic atau tetraplegic, yang sering disertai dengan retardasi mental, kejang atau ataksia (Dorlan, 2005).

Menurut Hidayat (2010), Kata cerebral itu sendiri adalah otak, sedangkan palsy adalah kelumpuhan atau lemahnya pengendalian otot dalam setiap pergerakan dan bahkan tidak terkontrol. Kerusakan otak tersebut mempengaruhi sistem motorik dan menyebabkan anak mempunyai koordinasi yang buruk pada gerak tubuh, keseimbangan yang buruk, pola-pola gerakan yang abnormal.

Kedua, Jenis-jenis Cerebral Palsy

Otak memiliki 3 bagian berbeda yang bekerjasama menjalankan dan mengontrol kerja otot yang berpengaruh terhadap pergerakan serta postur tubuh. Jika terjadi kerusakan pada bagian otak itulah yang membuat seseorang menderita Cerebral Palsy (Parkers dkk, 2005). Terdapat beberapa klasifikasi dari beberapa tipe CP berdasarkan tanda dan gejala yaitu:

1) Kekakuan/spastisitas. Spastik berarti otot-otot yang kaku atau kencang atau tegang. Kekakuan otot menjadikan gerakan kaku dan canggung/sulit. Instruksi-instruksi yang salah dari bagian otak yang rusak menyebabkan tubuh selalu dalam posisi abnormal yang khas, yang dirasa anak sulit untuk diubahnya. Spastik sendiri dibagi dalam 3 bagian:

a) Quadriplegia (empat anggota gerak)

Anak-anak yang keempat anggota geraknya terkena sering menderita kerusakan otak yang begitu parah sehingga mereka hampir tidak pernah bisa berjalan

b) Hemiplegia (satu sisi)

Sisi sehat normal ,lengan sisi sakit kadang spastik/kaku kadang lunglai dan hampir tidak berguna.

c) Diplegia (Keempat anggota gerak tetapi sisi atas lebih ringan. Tubuh bagian atas normal atau tanda-tandanya sangat kecil. Kedua tungkai jauh lebih parah

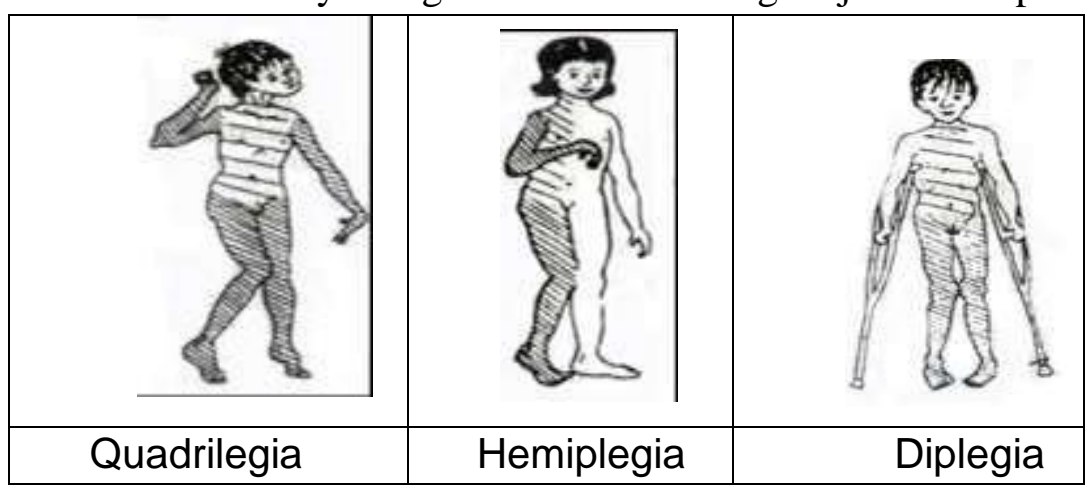

Gambar 1.1. Jenis-jenis Cerebral Palsy tipe spastik (Sumber: Buku Disable Village Children) 
2) Gerakan-gerakan tak terkontrol /Athetoid

Tipe athetoid adalah yaitu kondisi yang menunjukkan sulitnya kaki untuk berjalan, gerakan menggeliat-geliat dan sempoyongan sehingga sulit untuk mengontrol gerakannya. Letak kelainan pada CP athetoid terdapat pada ganglion basal. CP jenis ini menunjukan kekakuan pada tubuhnya, tetapi terdapat gerakan-gerakan yang tidak terkontrol yang terjadi sewaktu-waktu. Gerakan ini tidak dapat dikontrol, sehingga cenderung mengganggu aktivitas (Efendi, 2009).
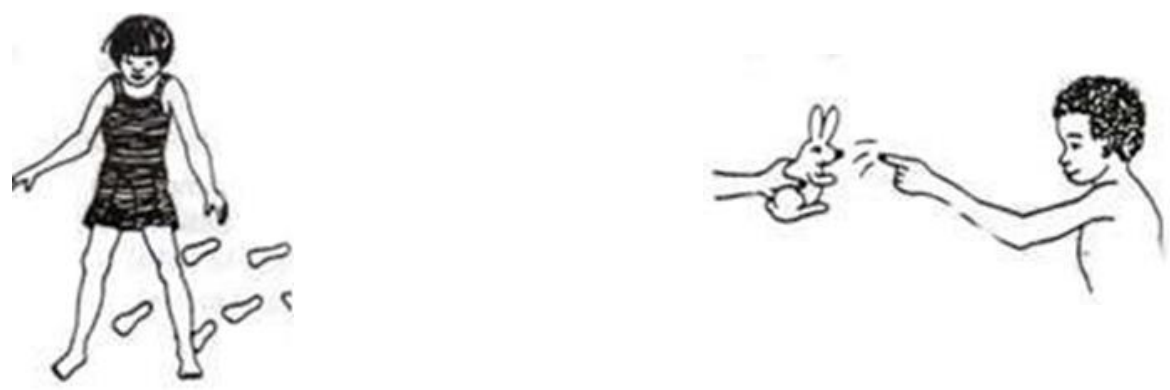

Gambar 1.2.Jenis-jenis Cerebral Palsy tipe Athetoid (Sumber: Buku Disable Village Children)

3) Keseimbangan buruk/ataksia

Kondisi ataksia tidak begitu umum dibandingkan dengan spastic dan athetoid. Kondisi ini disebabkan oleh luka pada bagian otak kecil yang terletak dibagian belakang kepala atau yang biasa disebut cerebellum yang memiliki fungsi mengontrol koordinasi dan keseimbangan pada kerja otot. Anak yang termasuk dalam CP ataksia memiliki ciri keseimbangan terganggu, pergerakan mengulang, refleks hipoaktif, terjadinya nistagmus yaitu gerakan ritmik pada mata yang tidak terkontrol sering menyebabkan penurunan ketajaman visual, gerakan involunter, terutama pada inisiasi penghentian gerak, atau berjalan tidak secara garis lurus, tremor terminal, dan melampaui tungkai (Maimunah, 2013). Ketika anak berbicara bisa artikulasi tidak jelas, dengan pengontrolan napas yang tidak teratur, sulit menelan, dan mudah tersedak (Farhana, 2013). Anak yang mengalami ataksia atau keseimbangan buruk, mengalami kesulitan untuk mulai duduk dan berdiri. Dia sering jatuh dan sangat canggung menggunakan tangannya. Misalnya anak mau meraih mainan dan tidak bisa. Semua ini normal pada anak-anak kecil tetapi pada anak yang menderita ataksia ini merupakan masalah yang lebih besar dan berlangsung lama (kadang-kadang seumur hidup).
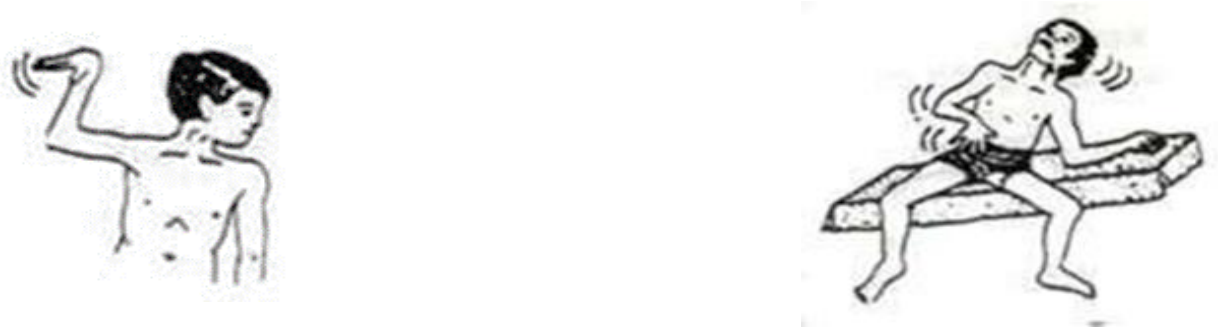

Gambar 1.3. Jenis-jenis Cerebral Palsy tipe ataksia (Sumber: Buku Disable Village Children) 


\section{4) Floppy/flaccid/lemas}

Yaitu kondisi anak yang lemas sekali. Karena tonus otot tidak ada sama sekali atau jika ada hanya minim sehingga anak hanya mampu berbaring saja. CP jenis floppy hampir mirip dengan kasus Poliomyelitis
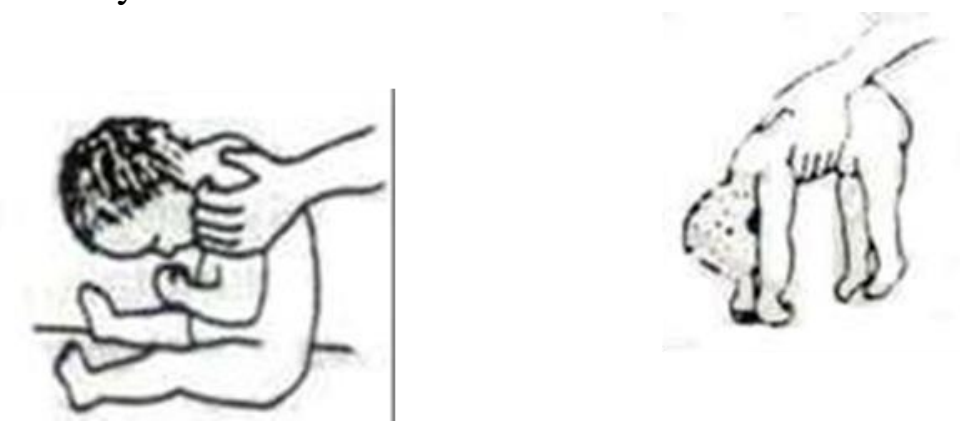

Gambar 1.4. Jenis-jenis Cerebral Palsy tipe ataksia (Sumber: Buku Disable Village Children)

\section{5) Tipe Campuran}

CP tipe ini memiliki kombinasi karakteristik misalnya campuran antara $\mathrm{CP}$ spastic, athetoid dan ataxia. Kecacatan dipengaruhi letak kerusakan yang terjadi pada otak. Letak kerusakan jenis ini di berada pada daerah pyramidal dan extrapyramidal. Bila kerusakan terjadi pada bagian pyramidal, kelainan yang akan muncul berbentuk spastic. Apabila terjadi di bagian extrapyramidal maka kelainan yang akan muncul berbentuk athetoid. Kondisi ini ditandai dengan jangka waktu yang lama di mana otot-otot ekstremitas atau batang tubuh tetap kaku, menolak setiap upaya untuk memindahkan mereka (Farhana, 2013).

Penelitian ini memiliki satu variabel bebas (X) dan satu variabel terikat yaitu Y Hubungan variabel bebas dan variabel terikat akan ditunjukkan pada gambar berikut ini.:

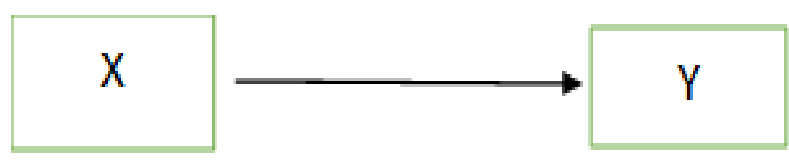

Gambar.1.5. Hubungan variabel bebas dan variabel terikat. Keterangan $X=$ Parenting training dan $Y=$ Mobilisasi sendi.

Jenis hubungan variabel yang digunakan oleh peneliti berdasarkan bagan deskripsi variabel di atas adalah hubungan simetris. Hubungan variable secara simetris artinya ada hubungan antara dua variabel, tetapi variabel yang satu tidak disebabkan atau dipengaruhi oleh variable lainnya.

Besarnya hubungan atau pengaruh parenting training terhadap mobilisasi sendi anak Cerebral Palsy sebesar 0,631. Jadi, pengaruhnya ada pada level "cukup". Berdasarkan pembuktian hipotesa, ketahui bahwa nilai Sig. F change adalah 0,000. Dengan demikian, dapat disimpulkan bahwa nilai probabilitas $0,05>0,000$, itu berarti ada hubungan yang signifikan antara variabel $\mathrm{X}$ dengan variabel $\mathrm{Y}$.

Jadi, Ho ditolak dan Ha diterima. Kegiatan parenting training berpengaruh secara signifikan terhadap perkembangan mobilisasi sendi Cerebral Palsy (Ha). Pengaruhnya tidak terlalu singnifikan, karena dari jenis hubungan yang dipakai sudah menunjukan bahwa kegiatan parenting training tidak ada hubungan langsung dengan mobilisasi sendi anak Cerebral Palsy. Kegiatan parenting training tidak berpengaruh secara signifikan terhadap perkembangan mobilisasi sendi Cerebral Palsy (Ho). 
Persentase hasil dari masing-masing kecamatan diperoleh nilai sebagai berikut : Kecamatan Singosari 73,4\%, dan Kec. Lawang sebesar 67\%,

Bertitiktolak dari kesimpulan di atas, peneliti membuat beberapa saran demi pengembangan dan peningkatan parenting training.

a) Perlu adanya monitoring dan evaluasi terhadap orang tua yang menerima parenting training. Yang melakukan MoNev adalah trainer dari PPRM Bhakti Luhur. MoNev ini perlu disertai dengan instrumen dan dilakukan evaluasi secara periodik.

b) Orang tua harus ada pro aktif untuk menanyakan kepada trainer jikalau menemukan kesulita-kesulitan dalam penanganan anak Cerebral Palsy.

c) Penelitian ini perlu ditindaklanjuti dengan membuat roadmap kajian ilmiah sembari dijadikan sebagai landasan untuk melakukan pengabdian kepada masyarakat khususnya orang tua yang memiliki anak Cerebral Palsy.

\section{KESIMPULAN}

Penelitian mengenai pengaruh parenting training terhadap peningkatan mobilisasi sendi bagi penyandang Cerebral Palsy di Kabupaten Malang dilatarbelakangi oleh minimnya pemahaman orangtua dalam menangani anaknya sehingga dari hasil pengamatan di lapangan banyak sekali anak Cerebral Palsy yang mengalami masalah dengan persendiannya antara lain spastik yang tinggi yang menyebabkan munculnya kontraktur pada persendian. Dengan segala upaya maka lewat program Indepth Right Yayasan Bhakti Luhur diadakanlah pelatihan atau parenting training mengenai mobilisasi sendi dengan harapan bahwa orangtua bisa menangani anaknya sendiri di rumah.

Dari hasil penelitian mengenai pengaruh parenting training terhadap mobilisasi sendi bagi penyandang disabilitas celebral palsy diketahui bahwa pengaruhnya hanya mencapai angka 0,631 ; angka ini belum belum menunjukkan pengaruh yang signifikan. Pengaruhnya masih berada pada level 'cukup'. Hasil ini tentu menjadi pekerjaan rumah bagi para trainer agar lebih jeli mencari cara agar parenting bisa dipahami oleh orangtua sehingga mereka bisa menerapkan dengan mudah hasil parenting yang mereka ikuti.

\section{DAFTAR PUSTAKA}

Chipulu, Protasio. 2013. Living With Cerebral Palsy: A Parents Guide to Managing Cerebral Palsy.

Guastaferro, Kate and Jhon R. Lutzker (Eds.). 2018. A Guide to Pragrams for Parenting Children with Autism Spectrum Disorder, Intellectual Disabilities or Development

Disabilities: Evidance-Base Guadance for Professionals. London and Philadelphia: Jessica Kingsley Publishers.

Hoghughi, Masud and Nicholas Log (Eds.), 2004. Handbook of Parenting: Theory and Research for Practice. London: SAGE Publications.

KN, Vykuntaraju 2014. Cerebral Palsy and Early Stimulation. India: Jaypee Brothers Medical Publishers, Ltd.

Miller, Freeman and Steven J. Bachrach. 2017. Cerebral Palsy: A Complete Guide for Caregiving. United States of America: Johns Hopkins University Press.

O'Reilly, Dermot. 2005. Conduct Disorder and Behavioural Parenting Training: Research and Practice. London and Philadelphia: Jessica Kingsley Publishers.

PPRBM Solo, (2010). Rehabilitasi Bersumberdaya Masyarakat: Pedoman RBM, Menuju ` 
Pembangungn Inklusif Bersumberdaya Masyarakat. Surakarta: PPRBM Solo.

Richardson, Joanna and Carol Joughin. 2002. Parent-Training Programmers for the Management of Young Children With Conduct Disorders. Great Britain: Cromwell Press Ltd, Trowbridge, UK.

Shepherd, Roberta B. (ed.), 2014. Cerebral Palsy in Infancy: Targeted Activity to Optimize early Growth and Development. China: Elsevier Churchille Livingstone.

Undang-Undang Republik Indonesia No. 8 Tahun 2016 Tentang Penyandang Disabilitas.

Undang-Undang Republik Indonesia No. 19 Tahun 2016 Tentang Pengesahan Ratifikasi Konvensi Hak-hak Penyandang Disabilitas United Nation - Convention of the Rights of Persons with Disability.

Suharjana. 2016. Teknik Analisa Data Dalam Penelitian dalam

https://www.google.com/search?client=opera\&q=http $\% 3 \mathrm{~A} \% 2 \mathrm{~F} \% 2 \mathrm{Fstaff} .+$ uny.ac.id\%2Fsites $\% 2$

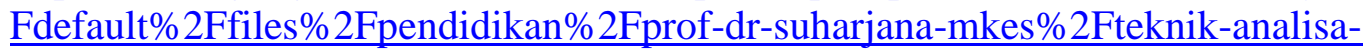

data.pdf.\&sourceid=opera\&ie=UTF-8\&oe=UTF-8 diakses hari Senin, 21 September 2020.

Wikipedia, (2016). Aksesibilitas, dalam https://id.wikipedia.org/wiki/Aksesibilitas diakses hari Senin, 21 September 2020. 